\title{
Associations of demographic, socioeconomic, self-rated health, and metastasis in colorectal cancer in Iran
}

\author{
Majid Taheri ${ }^{1}$, Mohammad Tavakol $^{2}$, Mohammad Esmaeil Akbari ${ }^{3}$, Amir Almasi-Hashiani $^{4}$, \\ Mahmoud Abbasi*1
}

Received: 8 Oct 2018

Published: 13 March 2019

\section{Abstract}

Background: Metastasis in Colorectal Cancer (CRC) is important because of the costs imposed on the individual. Self-Rated Health (SRH) can be useful for preventing cancer. Considering the role of Socio-Economic Status (SES) in CRC, our study was conducted to evaluate the relationship between demographic, SES, SRH, and metastasis of this type of cancer in Markazi province, Iran.

Methods: This cross-sectional, descriptive study (April to July 2018) was conducted on 411 patients suffering from CRC. These patients were hospitalized in one of the medical centers affiliated to Arak University of Medical Sciences (Arak, Iran), and with nonrandom sampling (available sampling) they were imported to the study. A reliable and valid questionnaire about levels of SES and SRH was filled by patients. For analyzing the data, Binomial logistic regression and chi-square tests were executed using Stata 11 software.

Results: The mean age was 60.01 years. According to the results of this study, as compared with poorest SES patients, the OR estimate of metastasis was $0.80(95 \%$ CI: $0.36,1.78)$ among the richest SES patients, in patients with age of $>60$ years was $9.92(95 \%$ CI: $1.53,64.39)$ in comparison with patients with age of $<40$ years, in male patients was 3.26 (95\% CI: $1.76,6.04)$ compared with female ones; in divorced/widowed patients was 0.52 (95\% CI: $0.11,2.51)$ in comparison with single ones; among those with academic level of education was 4.28 (95\% CI: 1.49, 12.26) compared with illiterate patients; and compared with poor SRH-age of patients, was 3.78 (95\% CI: 2.09, 6.85) among those with good SRH-age.

Conclusion: Patient's education and SES are important variables in metastasis and SRH of CRC in Iranian patients. All diagnostic tests and medical possibilities should be available for all individuals with adequate interventions. Patient's education and awareness should also be increased.

Keywords: Socio-economic status, Metastasis, Self-rated health, Colorectal cancer

Conflicts of Interest: None declared

Funding: Shahid Beheshti University of Medical Sciences

*This work has been published under CC BY-NC-SA 1.0 license.

Copyright $\odot$ Iran University of Medical Sciences

Cite this article as: Taheri M, Tavakol M, Akbari ME, Almasi-Hashiani A, Abbasi M. Associations of demographic, socioeconomic, self-rated health, and metastasis in colorectal cancer in Iran. Med J Islam Repub Iran. 2019 (13 March);33:17. https://doi.org/10.47176/mjiri.33.17

\section{Introduction}

Colorectal Cancer (CRC) is one of the most common malignancies which is the third most prevalent cancer in the world and the fourth cause of death from cancers (1). This type of cancer accounts for $10 \%$ of all cancers in men and $9.4 \%$ among women. It also has 783,000 new cases per year in the world (2). The incidence of CRC is

Corresponding author:DrMahmoud Abbasi,dr.abbasi@sbmu.ac.ir

1. Medical Ethics and Law Research Center, Shahid Beheshti University of Medical Sciences, Tehran, Iran

2. Sociology Department, School of Social Sciences, University of Tehran, Tehran, Iran

3. Cancer Research Center (CRC), Shahid Beheshti University of Medical Sciences, Tehran, Iran

4. Department of Epidemiology and Reproductive Health, Reproductive Epidemiology Research Centre, Royan Institute for Reproductive Biomedicine, ACECR, Tehran, Iran
$8.1 / 100000$ for men, and 7.5/100000 for women which takes the fifth place among men and the third one among women compared to all other types of cancers in Iran and the incidence is now increasing (3). CRC with 1.198 deaths per 100,000 , causes $13 \%$ of deaths from gastrointestinal cancers and $5.3 \%$ of non-accidental deaths (4).

\section{$\uparrow$ What is "already known" in this topic:}

Metastasis from CRC is a very important outcome, and some of its causative factors have been identified. However, the role of SES and SRH on metastasis of CRC has not been studied.

\section{$\rightarrow$ What this article adds:}

There is no significant association between SES and metastasis of CRC. However, the SRH has an effect on metastasis. Therefore, metastasis of CRC is not dependent on SES. The good SRH can be effective in reducing metastasis. 
Epidemiologic characteristics of colorectal cancer such as age distribution and incidence are different in various regions of the world so that the highest incidence has been observed in North America, Western Europe, Australia, and South America while the lowest incidence has been observed in Africa and Asia. This difference in incidence may be due to diversities in elements such as diet and environmental and demographic factors (5).

According to published studies, people with low SES will comprise a disproportionate number of these new cases (6). Regarding the reasons such as population growth, increasing life expectancy, relative increase in the elderly, annual increase of cancer incidence, and the acceleration of the changes in the components contributing to exacerbation of cancers in Iran, the rate of cancer growth is expected to be doubled over the next two decades and is considered as one of the major challenges of the health system (7). One of the factors affecting human health is SES, and for most people in the world, health status is primarily determined by the rate of economic and social progress such as per capita income, education level, nutrition, employment, housing, dependence ratio, household size, population growth rate, etc. According to the evidence, the greatest burden of disease and most health inequalities in the world are due to social factors (6).

The results of the studies indicate that the SRH has a strong relationship with objective assessments of wellbeing, health outcomes, and death. In other words, selfassessments of health outcomes predict both health outcomes and health risks throughout their lives (6). The most widespread criterion for SRH which is a global consensus is the following: How would you rate your general health status (8)? SRH can be effective in tracking individual health and preventing diseases. It can also prevent the recurrence and metastasis of cancers (9).

Economic and social factors, as well as demographic ones such as education, can be effective on SRH. In addition, knowledge of risk factors and those affecting metastasis in cancer can be related to both economic and demographic ones. Up to now, no study has been performed to assess the effect of economic and demographic factors on $\mathrm{SRH}$ as well as metastasis in patients with colorectal cancer. Therefore, the goal of this study is to evaluate the mentioned elements. Considering the relationship between these factors and metastasis of CRC, it is possible to prevent metastasis through increasing SRH.

\section{Methods}

\section{Sampling and population}

This study had a descriptive cross-sectional design and has been conducted on 411 patients. These patients were hospitalized in one of the medical centers of Arak University of Medical Sciences (Arak, Iran). Using non-random sampling (available sampling) they were imported into the study from April to July 2018. Main outcome of this study was to assess metastatic disease in each organ of the body. Metastasis of cancer was defined using medical records or asking the patients. Patients with the diagnosis of CRC more than one month ago were included. They should be able to communicate. The exclusion criteria included pa- tients with a severe psychological disease which prevented them from cooperating and not completing the questionnaire.

We calculated the sample size according to the incidence rate of CRC in Markazi Province that was equal to 47.44 reported in a previous study (10). The sample size was calculated by follows formula equal to 388 patients. 411 patients were included in the study considering the probability of attrition samples.

Informed consent satisfaction form was signed by all of the patients after illustrating the objectives of the study. Also, instruction of the questionnaire was given to each patient. Regarding the objectives of the study, the patients were provided with the necessary explanation, and the questionnaires were then distributed among them.

The protocol of the study was approved by the ethics committee of Shahid Beheshti University of Medical Sciences under grant number IR.SBMU.RETECH.REC. 1396.839 .

\section{Data gathering and questionnaire}

Data collection was done in three phases: the first phase included demographic factors such as age, sex, level of education, and marital and insurance status. The second phase included SES. A questionnaire designed by Garmaroudi et al. was used to measure the SES (11). This questionnaire includes questions about the women's level of education, the education of her husband, the infrastructure area, home expenses, and the number of rooms, facilities, and amenities (personal car, personal computer, more than one TV, refrigerator, washing machine, dishwasher, mobile phone, and traveling abroad). The score of reliability and validity of this questionnaire were 0.87 and 0.88 , respectively. SES was classified according to the PCA. Then, the PCA scores were sorted in descending order.

The SRH was examined by two questions: 1) in general, what would you say about your health? The answers were measured using a 5-point Likert scale ranging from 'excellent' (score 1) to 'poor' (score 5). The results were then grouped and divided into two categories of poor (poor, quite poor, and neither good nor bad) and good (very good and quite good). 2) SRH-age; How would you assess your general health status considering your age? The responses were classified as much worse, worse, slightly worse, not better, not worse, a little better, better, and much better (6).

\section{Statistical analysis}

The Principle Components Analysis (PCA) was used to measure the SES. PCA is a multivariate statistical technique for reducing a set of consistent variables to a small number of non-consistent ones. The first component of the analysis of the most variance is explained among the variables. Therefore, it is considered an index of SES for each individual (household). This component provides each household with a score, which reflects the SES of that household and can be used in analyses (12).

Binomial logistic regression and chi-square were used for analyzing the data with a $95 \%$ confidence interval. Statistical analyses was performed using Stata version 11. 
Patients' names were kept confidential, and their approval for cooperation were obtained before commencing the study.

\section{Results}

The average age of the patients was 56.56 year $(\mathrm{SD}=13.20)$. In general, $10.78 \%$ of patients were below 40 years old, and $37.75 \%$ were above 60 years old. $27.94 \%$ of the patients were illiterate or with primary education, while $14.71 \%$ had an academic education. More than half of the patients lived in Arak, and the others lived in the other cities.

The relationship of SRH with SES and demographic factors are shown in Table 1. According to these results, there was a significant relationship between $\mathrm{SRH}$ and gender, level of education, and metastasis $(\mathrm{p}<0.05)$.

The relationship of SRH-age with SES and demographic factors are shown in Table 2. According to these results, there was a significant relationship between SES of patients and SRH as compared with same-aged people $(\mathrm{p}<0.001)$. Furthermore, there was a significant relationship between marital status and SRH in comparison to those with similar age $(\mathrm{p}<0.05)$. There was also a meaningful relationship between the level of education and $\mathrm{SRH}$ as compared with same-aged people $(\mathrm{p}<0.001)$. In addition, a significant relationship was observed between metastasis and SRH in comparison with people of the same age $(\mathrm{p}<0.001)$.

Table 3 shows the relationship between CRC metastasis, patient's SRH, and demographic factors compared with same-aged people. Based on the results of adjusted OR, as compared with poorest SES patients, the OR estimate of metastasis was 0.80 (95\% CI: $0.36,1.78)$ among the richest SES patients. The OR estimate of metastasis in patients with age of $>60$ years was 9.92 (95\% CI: 1.53 , $64.39)$ in comparison with patients with age of $<40$ years. The OR estimate of metastasis in male patients was 3.26 (95\% CI: $1.76,6.04)$ compared with female ones. The OR estimate of metastasis in divorced/widowed patients was 0.52 (95\% CI: $0.11,2.51)$ in comparison with single ones.

Table 1. Relationship of Self-Rated Health in colorectal patients with Socio-Economic Status and demographic factors

\begin{tabular}{|c|c|c|c|c|c|}
\hline \multirow[t]{2}{*}{ Characteristic } & \multirow[t]{2}{*}{ Classification } & \multicolumn{2}{|c|}{ Self-Rated Health } & \multirow[t]{2}{*}{$\mathrm{F}$} & \multirow[t]{2}{*}{$\mathrm{p}$} \\
\hline & & Good (percent) & Poor (percent) & & \\
\hline \multirow[t]{3}{*}{ Socio-Economic Status } & Poorest & $127(93.38)$ & $9(6.62)$ & 3.42 & 0.181 \\
\hline & Middle & $119(86.86)$ & $18(13.14)$ & & \\
\hline & Richest & $120(88.24)$ & $16(11.76)$ & & \\
\hline \multirow[t]{4}{*}{ Age } & $<40$ & $38(86.36)$ & $6(13.64)$ & 3.93 & 0.269 \\
\hline & $41-50$ & $184(87.62)$ & $26(12.38)$ & & \\
\hline & $51-60$ & $130(93.53)$ & $9(6.47)$ & & \\
\hline & $>60$ & $175(94.59)$ & $10(5.41)$ & & \\
\hline \multirow[t]{2}{*}{ Gender } & Male & $107(97.27)$ & $3(2.73)$ & 9.33 & $0.002^{*}$ \\
\hline & Female & $259(86.91)$ & $39(13.09)$ & & \\
\hline \multirow[t]{3}{*}{ Marital Status } & Single & $17(94.44)$ & $1(5.56)$ & 0.77 & 0.856 \\
\hline & Married & $294(89.09)$ & $36(10.91)$ & & \\
\hline & Divorced/Widow & $52(91.22)$ & $5(8.78)$ & & \\
\hline \multirow[t]{3}{*}{ Level of Education } & Illiterate/Primary & $107(93.86)$ & $7(6.314)$ & 10.92 & $0.012^{*}$ \\
\hline & Secondary/Highs school & $150(92.859)$ & $12(7.41)$ & & \\
\hline & Academic & $59(81.94)$ & $13(18.06)$ & & \\
\hline \multirow[t]{2}{*}{ Insurance } & Yes & $355(89.65)$ & $41(10.35)$ & 0.05 & 0.821 \\
\hline & No & $11(91.67)$ & $1(8.33)$ & & \\
\hline \multirow[t]{2}{*}{ Metastasis } & Yes & $94(95.92)$ & $4(4.08)$ & 4.79 & $0.029^{*}$ \\
\hline & No & $169(88.02)$ & $23(11.98)$ & & \\
\hline
\end{tabular}

Table 2. Relationship of Self-Rated Health in comparison to same-aged people in colorectal patients with Socio-Economic Status and demographic factors

\begin{tabular}{|c|c|c|c|c|c|}
\hline \multirow[t]{2}{*}{ Characteristic } & \multirow[t]{2}{*}{ Classification } & \multicolumn{2}{|c|}{ Self-Rated Health-age } & \multirow[t]{2}{*}{$\mathrm{F}$} & \multirow[t]{2}{*}{$\mathrm{p}$} \\
\hline & & Good (percent) & Poor (percent) & & \\
\hline \multirow[t]{3}{*}{ Socio-Economic Status } & Poorest & $47(34.56)$ & $89(65.44)$ & 20.58 & $<0.001$ \\
\hline & Middle & $54(39.42)$ & $83(60.58)$ & & \\
\hline & Richest & $82(60.29)$ & $54(39.71)$ & & \\
\hline \multirow[t]{4}{*}{ Age } & $<40$ & $21(47.73)$ & $23(52.27)$ & 3.08 & 0.379 \\
\hline & $41-50$ & $101(48.10)$ & $109(51.90)$ & & \\
\hline & $51-60$ & $54(38.85)$ & $85(61.15)$ & & \\
\hline & $>60$ & $7(46.67)$ & $8(53.33)$ & & \\
\hline \multirow[t]{2}{*}{ Gender } & Male & $43(39.09)$ & $67(60.91)$ & 2.02 & 0.155 \\
\hline & Female & $140(46.98)$ & $158(53.02)$ & & \\
\hline \multirow[t]{3}{*}{ Marital Status } & Single & $7(38.89)$ & $11(61.11)$ & 13.87 & 0.003 \\
\hline & Married & $154(46.67)$ & $176(53.33)$ & & \\
\hline & Divorced/Widow & $21(36.84)$ & $36(63.16)$ & & \\
\hline \multirow[t]{3}{*}{ Level of Education } & Illiterate/Primary & $45(39.47)$ & $69(60.53)$ & 19.95 & $<0.001$ \\
\hline & Secondary/Highs school & $58(35.80)$ & $104(64.20)$ & & \\
\hline & Academic & $44(61.11)$ & $28(38.89)$ & & \\
\hline \multirow[t]{2}{*}{ Insurance } & Yes & $178(44.95)$ & $218(55.05)$ & 0.05 & 0.822 \\
\hline & No & $5(41.67)$ & $7(58.33)$ & & \\
\hline \multirow[t]{2}{*}{ Metastasis } & Yes & $29(29.59)$ & $69(70.41)$ & 22.23 & $<0.001$ \\
\hline & No & $113(58.85)$ & $79(41.15)$ & & \\
\hline
\end{tabular}


Table 3. Binomial logistic regression results examining the relationship of colorectal cancer metastasis with Socio-Economic Status and demographic factors

\begin{tabular}{|c|c|c|c|}
\hline \multicolumn{2}{|l|}{ Characteristic } & Crude & Adjusted $^{*}$ \\
\hline & & OR $(95 \% \mathrm{CI})$ & OR $(95 \% \mathrm{CI})$ \\
\hline \multirow[t]{3}{*}{ Socio-Economic Status } & Poorest & Reference & Reference \\
\hline & Middle & $0.90(0.49,1.65)$ & $0.88(0.42,1.86)$ \\
\hline & Richest & $0.80(0.44,1.46)$ & $0.80(0.36,1.78)$ \\
\hline \multirow[t]{4}{*}{ Age } & $<40$ & Reference & Reference \\
\hline & $41-50$ & $1.22(0.48,3.09)$ & $2.17(0.74,6.32)$ \\
\hline & $51-60$ & $2.21(0.86,5.64)$ & $3.74(1.16,11.94)^{*}$ \\
\hline & $>60$ & $4.71(1.02,21.65)$ & $9.92(1.53,64.39)^{*}$ \\
\hline \multirow[t]{2}{*}{ Gender } & Female & Ref & Ref \\
\hline & Male & $3.80(2.23,6.49)$ & $3.26(1.76,6.04)^{*}$ \\
\hline \multirow[t]{3}{*}{ Marital Status } & Single & Reference & Reference \\
\hline & Married & $0.69(0.23,2.06)$ & $0.55(0.14,2.08)$ \\
\hline & Divorced/Widow & $0.63(0.17,2.29)$ & $0.52(0.11,2.51)$ \\
\hline \multirow[t]{4}{*}{ Level of Education } & Illiterate & Reference & Reference \\
\hline & Primary & $1.24(0.66,2.30)$ & $1.34(0.64,2.82)$ \\
\hline & Highs school & $0.88(0.41,1.89)$ & $1.65(0.62,4.37)$ \\
\hline & Academic & $1.36(0.61,3.01)$ & $4.28(1.49,12.26)^{*}$ \\
\hline \multirow[t]{2}{*}{ Insurance } & No & Reference & Reference \\
\hline & Yes & $0.36(0.08,1.68)$ & $0.18(0.03,1.03)$ \\
\hline \multirow[t]{2}{*}{ Self-Rated Health } & Poor & Reference & Reference \\
\hline & Good & $0.31(0.10,0.91)$ & $0.44(0.12,1.62)$ \\
\hline \multirow[t]{2}{*}{ Self-Rated Health-age } & Poor & Reference & Reference \\
\hline & Good & $3.40(2.02,5.72)$ & $3.78(2.09,6.85)^{*}$ \\
\hline
\end{tabular}

*Adjusted for all variables in the table

Compared with illiterate patients, the OR estimate of metastasis was 4.28 (95\% CI: $1.49,12.26)$ among those with academic level of education. In addition, compared with poor SRH-age of patients, the OR estimate of metastasis was 3.78 (95\% CI: $2.09,6.85)$ among those with good SRH-age.

\section{Discussion}

In this study, the Chi-square test was used to examine the relationship between SES, demographic factors, and SRH. Logistic Regression was also used to study the relationship between different factors and metastasis of CRC. There was a significant relationship between gender and SRH. Women have weaker SRHs compared with men. Another kind of SRH that was investigated in this study was SRH in comparison to same-aged people that showed a significant relationship with age, SES, education, and metastasis of cancer. In Vahdaninia's study(13) the OR estimate of SRH was 1.01 among women compared with men. In terms of the academic level of education, OR estimate of SRH was 1.27 among illiterates, that was consistent with our results. In our study, there was no significant relationship between marital status and SRH while in Vahdaninia's study OR estimate of SRH was 1.95 among divorced women compared with those who were married. Furthermore, compared with "very bad" level of SES, the OR estimate of SRH was 2.81, in. "very good" level. This relationship is not seen in our study. According to the results of our study, age had no significant relationship with SRH and SRH-age. Therefore, at an older age, a better SRH was reported compared with an earlier age. Based on this relationship, it can be interpreted that for higher ages weaker SRH is reported, because they are sicker and have poorer physical conditions. The relationship between age and SRH has been proven in Vahdaninia's study. Additionally, lower SRH is reported for patients with metastasis compared with those without metastasis. It can be in- ferred that those with metastasis, are in worse health due to the worse condition of the disease. Up to now, no study has been performed to evaluate the effect of metastasis on SRH. However, in Vahdaninia's study, it was found that, compared with healthy people, OR estimate of bad SRH was 7.38 among patients who had a chronic disease(13). Level of education was a significant factor in assessing the SRH. Based on the results, a lower educational level was a predictor of a higher level of health as compared to the level of academic education. This finding is confirmed by the results of another study in Iran. This study evaluates the effect of educational inequalities on health status reported by individuals or health self-reported questionnaires. The results of the regression analysis showed that there is a reverse relationship between educational level and SRH (14). In a study in the United Kingdom, the effect of social inequality on the self-assessment of the health of individuals was investigated. Based on the results, the effect of education and important health behaviors on individuals was revised in line with the factors of social inequality. In fact, social inequality and age have been effective factors in self-assessment of people's health (15).

According to previous studies, marital status has been shown to be a predictor of the level of health reported by individuals. In a study in Syria, married women report lower levels of health compared with single people (16). Another study in the United States has reported married life as a positive factor affecting the SRH (17). The results of our study showed that patients with higher SES levels have higher SRH-age. This finding confirms the results of a previous research, showing the reverse effect of socioeconomic and income levels on the health status of individuals in societies. In fact, people with low-income levels report worse health status compared with higher income levels(6). In Chyke's study, SES was assessed by either individual-level education or neighborhood measures and 
was associated with $\mathrm{CRC}$ risk, even after accounting for other risk factors. The relationship between SES and CRC was the strongest in the rectum and the weakest in the right colon (18). Our results showed that metastasis was related to gender. Although this relationship was not significant, it showed that men had metastasis more than women. Effect of gender on cancer was demonstrated in other previous studies(6). In our study, the relationships of metastasis with SES, education, and SRH were demonstrated by logistic regression. One of the elements that can contribute to cancer metastasis is the diagnosis of the disease. Cancer is more easily diagnosed at an early stage, less likely to be metastatic. Early detection of cancer is directly related to SES (19).

Higher education will make the person study more and have more information about the disease and its prevention. Educated people have sufficient knowledge and skills for receiving health messages at the right time and have more competence for accessing health services (20) since they know the importance of follow-up. In a study by Albano, it was shown that the mortality rate for colon cancer in people with less than 8 years of education was 2.2 times higher than those who had 17 years of education or more (21). In Ciccone's study, it was found that a lower level of education ( $<9$ years) was equal to more time between symptoms onset and surgical treatment (22). This outcome confirms the results of this study.

In our study, OR estimate of metastasis was 1.46 among uninsured patients compared with insured ones. However, this relationship was not statistically significant. Insurance did not correlate with complete treatment. It correlated with regular follow-up. The time for treatment of cancer is short, but follow-up is a prolonged process. Therefore, insurance cover affects the follow-up process rather than treatment. There are different results regarding the relationship between insurance and colon cancer in various studies. Roetzheim et al. found that patients who were uninsured or insured by Medicaid had higher mortality rate (after adjusting for age, gender, the stage on diagnosis, treatment, comorbidities, marriage status, smoking, and socioeconomic level) (23). Ward also found that those who were uninsured or insured by Medicaid had 1.6 times higher mortality rate in a 5-year follow-up compared to people with private insurance. This may be due to various factors such as access to care, variations in tumor size, grade, delay in treatment initiation, differences in receiving treatment with standard instructions, and outcomes of treatments. Some of these outcomes including the completeness of surgical resection, differences in supportive care, and completion of the full course of therapy (24).

Our study had some limitations. The possibility of recall bias was one of these limitations which was an issue as some patients might have wrongly estimated SES before the diagnosis of CRC. In addition, despite the strong OR estimate for some relationships, they were not significant, which is due to low sample size.

\section{Conclusion}

In conclusion, patient's combined socioeconomic status, as well as demographic factors such as education, are important variables in the metastasis of CRC and SRH. All diagnostic tests and medical possibilities should be available for all individual with adequate interventions. Furthermore, the SRH can improve diagnostic and prevention measures which can lead to rapid diagnosis of disease and reduction in metastasis. In addition, adequate insurance cover for people is recommended.

\section{Acknowledgments}

This study is a part of the PhD thesis of Dr. Majid Taheri in the field of Medical Sociology that is funded by Shahid Beheshti University of Medical Sciences.

\section{Ethical statement}

The Research Ethics Committee of Shahid Beheshti University of Medical Sciences approved this study and participants provided written informed consent for voluntary participation in the study (Ethical Code: IR.SBMU.RETECH.REC.1396.839).

\section{Conflict of Interests}

The authors declare that they have no competing interests.

\section{References}

1. Akhoond M, Kazemnejad A, Hajizadeh A, Ganbary Motlagh A, Zali M. Comparison of influential factors affecting survival of patients with colon and rectum cancer using competing risks model. Koomesh. 2011;12(2):11928. (Persian).

2. Bray F, Ferlay J, Soerjomataram I, Siegel RL, Torre LA, Jemal A. Global cancer statistics 2018: GLOBOCAN estimates of incidence and mortality worldwide for 36 cancers in 185 countries. CA Cancer J Clin. 2018;68(6):394-424.

3. Islamic Republic of Iran Ministry of Health and Medical Education Office of Deputy Minister for Health Center for disease control cancer offfice. Iranian annual National Cancer Registration Report. 2005-2006.2007 March (Persian).

4. Sadjadi A, Malekzadeh R, Derakhshan MH, Sepehr A, Nouraie M, Sotoudeh M, et al. Cancer occurrence in Ardabil: Results of a population-based Cancer Registry from Iran. Int J Cancer. 2003;107(1):113-8.

5. Dhillon P, Mathur P, Nandakumar A, Fitzmaurice C, Kumar GA, Mehrotra R, et al. The burden of cancers and their variations across the states of India: the Global Burden of Disease Study 1990-2016. Lancet Oncol. 2018;19(10):1289-306.

6. Le H, Ziogas A, Lipkin SM, Zell JA. Effects of socioeconomic status and treatment disparities in colorectal cancer survival. Cancer epidemiology, biomarkers \& prevention: a publication of the American Association for Cancer Research, cosponsored by the American Society of Preventive Oncology. 2008;17(8):1950-62.

7. Zendehdel K, Hasanlou Z, Sedighi Z, Nahvijou A, Mousavi Jarrahi S, Malekzadeh R, et al. Improving quality of cancer registration in iran. Part2: Suggesting new na- 
tional cancer registration program in iran, based on comparative study of 18 countries. Hakim Health Sys Res. 2010;12(4):50-7. (Persian).

8. McAlpine DD, McCreedy E, Alang S. The Meaning and Predictive Value of Self-rated Mental Health among Persons with a Mental Health Problem. J Health Soc Behav. 2018;59(2):200-14.

9. Zarragoitia A, Urkaregi A. Inkesten emaitzetan oinarrituriko balorazio-adierazle orokorra sortzeko proposamena. EKAIA. 2014

10. Almasi A, Shamsi M, Eshrati B, Farzam R, Alimoradi K, Rahmati L. The epidemiology of gastrointestinal cancers (Stomach, esophageal, colorectal) In Markazi province during 2005-2010. J Neyshabur Uni Med Sci. 2014;2(2):22-7.

11. Garmaroudi GR, Moradi A. Socio-economic status in Iran: a study of measurement index. Payesh. 2010;9(2):137-44. (Persian).

12. Vyas S, Kumaranayake L. Constructing socioeconomic status indices: how to use principal components analysis. Health Policy Plan. 2006;21(6):459-68.

13. Vahdaninia M, Ebadi M. How are people evaluating their health? A study of health from the point of view of the Iranian people (persian). JHS. 2011;10(3):355-63.

14. Montazeri A, Goshtasebi A, Vahdaninia M. Educational inequalities in self-reported health in a general Iranian population. BMC Res Notes. 2008;1(1):50.

15. McFadden E, Luben R, Bingham S, Wareham N, Kinmonth AL, Khaw KT. Social inequalities in self-rated health by age: Cross-sectional study of 22457 middleaged men and women. BMC Public Health. 2008;8(1):230.

16. Asfar T, Ahmad B, Rastam S, Mulloli TP, Ward KD, Maziak W. Self-rated health and its determinants among adults in Syria: a model from the Middle East. BMC Public Health. 2007;7(1):177.

17. Finnegan L, Marion L, Cox C. Profiles of self-rated health in midlife adults with chronic illnesses. Nurs Res. 2005;54(3):167-77.

18. Doubeni CA, Laiyemo AO, Major JM, Schootman M, Lian M, Park Y, et al. Socioeconomic status and the risk of colorectal cancer: an analysis of over one-half million adults in the NIH-AARP Diet and Health Study. Cancer. 2012;118(14):3636.

19. Cavalli-Björkman N, Qvortrup C, Sebjørnsen S, Pfeiffer P, Wentzel-Larsen T, Glimelius B, et al. Lower treatment intensity and poorer survival in metastatic colorectal cancer patients who live alone. BJC. 2012;107(1):189.

20. Galobardes B, Shaw M, Lawlor DA, Lynch JW, Smith GD. Indicators of socioeconomic position (part 1). Br J Prev Soc Med. 2006;60(1):7-12.

21. Albano JD, Ward E, Jemal A, Anderson R, Cokkinides VE, Murray T, et al. Cancer mortality in the United States by education level and race. J Natl Cancer Inst. 2007;99(18):1384-94.

22. Ciccone G, Prastaro C, Ivaldi C. Access to hospital care, clinical stage and survival from colorectal cancer according to socio-economic status. Ann Oncol. 2000;11:1201-4.
23. Roetzheim RG, Pal N, Gonzalez EC, Ferrante JM, Van Durme DJ, Krischer JP. Effects of health insurance and race on colorectal cancer treatments and outcomes. Am J Public Health. 2000;90(11):1746.

24. Ward E, Halpern M, Schrag N, Cokkinides V, DeSantis C, Bandi P, et al. Association of insurance with cancer care utilization and outcomes. CA Cancer J Clin. 2008;58(1):9-31. 